\title{
"Vos, señor, la escribiste a la luna" Aprendizaje, discurso y prácticas epistolares en la España Moderna $^{1}$
}

\author{
"Vos, señor, la escribiste a la luna" \\ Epistolary Initiation, Discourse and Practices in Early \\ Modern Spain
}

\author{
ANTONIO CASTILLO GÓMEZ \\ Universidad de Alcalá - SIECE - Grupo LEA
}

\begin{abstract}
Este artículo esboza un acercamiento a los usos epistolares en la España de los siglos XVI y XVII. Por un lado, se ocupa de las posibilidades que había en la época para aprender a escribir cartas y el papel desempeńado por ciertos intermediarios de escritura que ejercieron esa tarea cuando la persona era analfabeta o carecía de la solvencia suficiente en el manejo de un género tan codificado como el epistolar. Y por otro, se reflexiona sobre la relación establecida entre el protocolo textual y la materialidad del escrito con objeto de hacer factible el pacto de comprensibilidad que implica la escritura de una carta. A este respecto se revisan determinados principios de la teoría epistolar sustentada en los manuales áureos y su contraste o no con la realidad que testimonian las cartas mismas.
\end{abstract}

Palabras clave: escritura epistolar, teoría epistolar, aprendizaje, intermediarios de escritura, prácticas, representaciones, España, temprana Edad Moderna, Siglos XVI y XVII.

This article sketches an approach to the study of epistolary practices in sixteenth- and seventeenthcentury Spain. On the one hand it considers the possibilities in that period of learning to write letters and the role played by certain intermediaries who undertook writing for others in cases of illiteracy or insufficient familiarity with the codes of writing letters. On the other it reflects on the relation between textual protocols and the materiality of writing in order to enhance the implicit pact of understanding required by letter-writing. Thus the article revisits certain aspects of the theory of epistolarity encoded in early modern instruction books, and reflects on their relations with the realities enshrined in the letters themselves.

Keywords: letter-writing, epistolary theory, apprenticeship, writing intermediaries, representations, Spain, Early Modern period, sixteenth and seventeenth centuries.

\footnotetext{
${ }^{1}$ Este trabajo se ha realizado en el marco del proyecto de investigación, "Scripta in itinere". Discursos, formas y apropiaciones de la cultura escrita en espacios públicos desde la primera Edad Moderna a nuestros días (2005-2008), financiado por el Ministerio de Economía y Competitividad (Ref. HAR2014-51883-P).
} 
"En tres cosas se conosce el hombre loco o el hombre cuerdo, es a saber: en refrenar la yra, en governar su casa y en escrevir una carta, porque estas tres cosas son tan diffíciles de alcançar, que ni se pueden con hazienda comprar ni aun por amistad emprestar."

(Guevara 2004: 303)

\section{INTRODUCCIÓN}

Las Epistolas familiares de fray Antonio de Guevara, obispo de Mondoñedo y cronista del emperador Carlos V, se publicaron en Valladolid en dos volúmenes, el primero en 1539 y el segundo en 1542, impresos en el taller de Juan de Villaquirán. Influidas por las Lettere de Pietro Aretino, cuyo primer tomo salió de tipografía en Venecia en enero de 1538, las Epistolas disfrutaron de un importante éxito editorial tanto en España como en otros países europeos. Amén de destilar apreciaciones sobre usos y mentalidades del tiempo, conforme al valor instructivo que tuvieron entonces otras antologías (Braida 2009), en ellas se compendia una teoría del género epistolar orientada principalmente a la sociedad de corte. La deferencia que se pone en los buenos hábitos es parte de la preocupación humanista por la escritura (Egido 2012), explicitada en la amplia producción de artes de escribir que vieron la luz en los siglos XVI y XVII (Martínez Pereira 2006; Gutiérrez Cabero 2015). A fin de apreciar esta dignificación de la escritura basta recordar que, en uno de los grabados que ilustraron la obra Pentaplon christianae pietatis de Antonio de Honcala (Alcalá de Henares: Juan de Brocar, 1546), el paso de la infancia a la edad madura fue simbolizado mediante la sustitución de la cuna y los juguetes por la pluma y el libro.

En esa coyuntura, la carta se convirtió en un instrumento de comunicación de amplio vuelo. Con la llegada de la Edad Moderna, a medida que el mundo se fue ensanchando por otros continentes y los desplazamientos de población se hicieron más masivos y frecuentes, la carta se hizo más necesaria para gobernar en la distancia, cristianizar las nuevas tierras, difundir informaciones, intercambiar ideas, gestionar negocios o preservar vínculos familiares. Así lo acredita el crecimiento exponencial de la correspondencia durante esa época, implicando a todos los sectores sociales, obviamente en distinta medida (Bouza 2005; Testón Núñez y Sánchez Rubio 2008; Antón Pelayo 2011; y Castillo Gómez 2013). En dicho período se consolidó una auténtica sociedad epistolar, que se entiende mejor considerando la incidencia de los siguientes factores:

a) El aumento del alfabetismo, estimulado por mayores oportunidades para aprender merced a la labor de maestros particulares, cabildos municipales y órdenes religiosas.

b) La implantación política y social de la escritura, cuya lógica se extendió desde las esferas del poder a muchas casas particulares.

c) El impulso aportado por una serie de circunstancias, como la emigración, la guerra o la cárcel, que, al ocasionar el distanciamiento físico entre personas, crearon el caldo 
de cultivo para que la escritura mostrara su capacidad a la hora de preservar lazos y suturar heridas.

d) La organización del correo como servicio del Estado y la articulación de una red de caminos o postas, para las rutas terrestres, y de flotas, para las marítimas.

e) La extensa nómina de manuales y formularios epistolares, manuscritos y especialmente impresos, así como la publicación de antologías o "libro de cartas".

Como consecuencia de esto, los autores y autoras de las cartas de la Edad Moderna no se encuentran solamente entre quienes desempeñaron actividades relevantes en el plano político, cultural, social o comercial, sino también entre personas más corrientes. De todos modos, es pertinente matizar que la conservación de unas y otras misivas es bastante desigual. $\mathrm{Si}$ las correspondencias vinculadas con las élites han sido más favorecidas, bien porque sus propietarios tuvieran una conciencia clara de su valor, bien porque fuera conveniente guardarlas en el desempeño de asuntos políticos, comerciales o de otra índole; por lo general, no ha ocurrido lo mismo con las cartas referentes a las clases subalternas, a menos que se trate de súplicas dirigidas a las autoridades. Pero esto no significa que no existan, como a veces se ha pensado apoyándose en el amplio analfabetismo de la gente común en los siglos modernos, ${ }^{2}$ sino que los procedimientos que han motivado su conservación son otros. En este sentido, la mayor parte de los testimonios conocidos, como los que puedan exhumarse en el futuro, se localizan en expedientes generados por instancias administrativas y judiciales que exigieron la presentación o incautación de cartas personales como parte de las averiguaciones efectuadas a la hora de resolver distintos asuntos. Obviamente, esta circunstancia condiciona el perfil que tienen muchas de dichas misivas, sobre todo cuando se trata de documentos requeridos por los tribunales y órganos de justicia, inquisitorial, civil, criminal o eclesiástica (Sánchez Rubio y Testón Núñez 1999; Usunáriz 2015).

\section{Aprendizajes E INTERMEDIARIOS}

Para comprender la importancia de la civilización epistolar desplegada en la Edad Moderna es preciso que nos acerquemos, en primer lugar, a las posibilidades que había para aprender a escribir cartas, por un lado, $y$, por otro, al papel desempeńado por ciertos intermediarios que ejercieron su labor cuando la persona era analfabeta o carecía del adiestramiento suficiente en un género de escritura tan codificado como el epistolar. Quienes accedieron a las escuelas de gramática y a los estudios superiores tuvieron la oportunidad de

\footnotetext{
${ }^{2}$ A partir de los datos sistematizados en su día por Antonio Viñao Frago (1999), para la España de los siglos XVI y XVII se obtendría un valor medio de 53,6\% de varones analfabetos y $85,3 \%$ de mujeres, que naturalmente debe ser tomado a título meramente indicativo dada la pluralidad de matices que admite el concepto "alfabetismo" en la Edad Moderna y la heterogeneidad de las fuentes empleadas para medirlo en términos numéricos. Para otros ámbitos del mundo occidental, Graff 1981 y 1987.
} 
profundizar en ese conocimiento completándolo con una mayor destreza que pasaba por el ejercicio constante y la lectura continuada de las cartas de los autores clásicos, especialmente Cicerón (Grendler 1989: 121-125). Pero esto nos sitúa en un plano distinto, el de quienes habrían de desempeñar tareas de secretario o dedicar su vida a las letras.

Sin llegar a ese extremo lo que ahora me parece más relevante es dejar anotado que para muchos, el primer contacto con la escritura de cartas se produjo al aprender las primeras letras. Así, en los contratos de enseñanza suscritos con maestros, clérigos, bachilleres o mercaderes es habitual que estos se comprometan a enseñar a leer y a escribir, en algunos casos incluso como empeño principal. Nótese que en la Sevilla de finales del siglo XV, Juan de Cisneros, escribano de enseñar mozos, acordó con Gonzalo de Formisedo, tutor de Juan Gómez, cuyo padre había muerto, que enseñaría a este a escribir y leer una carta a cambio de 450 maravedís pagaderos en tres partes: la primera al inicio, la segunda cuando el pupilo hubiera aprendido a escribir en letra redonda y la tercera una vez que fuera capaz de leer y escribir una carta (Cit. en Sánchez Herrero y Pérez González 1998: 73-74). Abunda en lo mismo el contrato que el 20 de septiembre de 1565 suscribieron Francisco de Bastián Pérez y Pedro Bravo, clérigo, "maestro de los nińos de la doctrina" de la villa de Valladolid, para que este admitiera a Gaspar, hermano del primero, como aprendiz durante un año a fin de "amostrar y ensenar a leer y a escrevir una carta mensajera" (Cit. en Herreros Jiménez y Diéguez Orihuela 2008: 146). En la misma ciudad, en junio de 1596, el maestro de niños García de Bariones contrató con Alonso Martín, barrero, que durante dos años enseñaría al hijo de éste, Juan Martín, a "leer tirado y redondo castellano" y a escribir "una carta o memoria que se le mande de una de las formas que se usan al presente" (Ibíd.: 171).

Explicar, empero, cómo podía desarrollarse ese acto de enseñanza es algo que no detallan dichos documentos. En su lugar podemos traer a colación textos como el conocido diálogo "Escribir y redactar" del maestro Luis Vives, donde relata una escena que bien pudo acontecer durante la estancia de Antonio de Nebrija en la Universidad de Alcalá entre 1513 y 1522. En una mañana cualquiera, Nebrija, subido en el estrado, disertaba sobre la utilidad de la escritura. Una lección que escuchó atentamente, aunque desprovisto de pluma o tablillas donde tomar nota, un mancebo de nombre Manrique. A la salida lo comentó con su joven amigo Mendoza, quien no había tenido el placer de asistir. Éste, atraído por las palabras de su compañero, no dudó en pedirle más detalles sobre el contenido de la exposición. Manrique no recordaba todo pero sí había retenido el pasaje en que el maestro, "dijo -apoyado en la autoridad de no sé qué autor- que no hay camino más corto para un buen orador que escribir con corrección y fluidez". A renglón seguido los dos mancebos se pusieron a discutir sobre el sentido de esas palabras y la importancia del saber. Tanto que decidieron entregarse a la escritura para escapar a la ignorancia del vulgo. Manrique reconoció que hacía "las letras torcidas, desiguales e ilegibles". Necesitaban, pues, de alguien que les enseñase el arte de escribir y qué mejor que acudir a Nebrija. Se presentaron en la casa que éste tenía alquilada junto a la iglesia de San Justo y Pastor para que les enseñara su "mismo arte, si es que quieres y hay posibilidad”. Amén del interés y la voluntad de los muchachos, poco más necesitaba Nebrija para atender sus deseos. Se produce entonces un jugoso diálogo entre el maestro y los alumnos 
en el que se repasan los instrumentos de escritura, el modo de preparar la pluma y la tinta o las calidades y tipos del papel, hasta que al final el maestro termina dándoles una muestra:

MANRIQUE.- Danos ya, si te parece, una muestra.

Maestro.- Primero, el abecedario; después, por sílabas y, finalmente, las palabras articuladas de la forma siguiente: "Aprende, niño, aquello que te haga más sabio y, por ende, mejor. Las voces o fonemas son signos vivos entre los presentes, y las letras entre los ausentes". Escribir esto y, después de comer o mañana, volved por aquí para que yo corrija lo que habéis escrito (Vives 1987: 81-91).

¡Quién sabe si otro día la muestra pudo ser una carta! No sería muy descabellado pensarlo si hermanamos la evocación planteada por esta pieza del humanista valenciano con lo que antes hemos apuntado a propósito del aprendizaje de las primeras letras. Por el momento falta aquilatar documentalmente si en ese proceso se emplearon tratados y formularios epistolares, aunque no cabe descartarlo. Sin perder de vista que el contenido de estos apela preferentemente a un público de cortesanos y burócratas, tal vez no sea inútil recordar que en 1629 el librero madrileño Miguel Martínez tenía en su tienda un total de 550 formularios de cartas (Dadson 1998; 318). En la misma dirección incide el hecho de que Jerónimo Paulo de Manzanares justificara la publicación de su Estilo y formulario de cartas familiares (Madrid: Alonso Martín, 1607) por la fortuna que la obra había cosechado en una versión anterior, anónima pero suya, de la que al parecer se habían vendido casi dos mil copias: "y fue tan bien recebido de todos que en breve tiempo se distribuyeron casi dos mil cuerpos que imprimí, en nombre de Diego Martínez, librero de Alcalá” (Manzanares 1607: Prólogo). Asimismo, Juan de Icíar sostuvo que su Nuevo estilo de escrevir cartas mensageras (Zaragoza: Agustín Millán, 1552) salía a la luz "con el desseo de hazer fructo a muchos". Siendo evidente la finalidad comercial de este tipo de razones, puestas en relación con los datos anteriores coinciden en señalar la copiosa difusión que pudieron alcanzar los manuales epistolares en la Edad Moderna, ora por sus orientaciones sobre ciertos aspectos de la escritura de cartas, ora porque se prestaran a lecturas de otra índole. Por otro lado, pese a que las cartas, como el resto de documentos públicos y privados de la época, no se incluyen como ejemplos en los tratados de escritura, sí constan algunas alusiones. Francisco Lucas, por ejemplo, expone en su Arte de escribir (Madrid, Francisco Sánchez, 1580) que la letra debe ir mudando hasta quedar en el "tamańo ordinario que se tiene para cartas y escrituras" (Lucas 2005: 10v, del facsímil).

Además de esto, las cartas en sí mismas fueron también una vía de aprendizaje, a veces propiciado por el liderazgo y la admiración despertados por sus autores y autoras. De las misivas de María de Cazalla se decía que corrían encuadernadas o cosidas en la Castilla de 1520 (Cit. en Ortega-Costa 1978: 73). Sabido es también que los autógrafos espirituales de Teresa de Jesús circularon por los conventos de carmelitas y entre gentes de la época, desarrollándose incluso un culto a su escritura que hizo que muchos terminaran fragmentados y convertidos en reliquias corporales (Álvarez 2001: 341), al tiempo que desde 
1582 se libró una batalla por la conservación de sus cartas (Garriga Espino 2015: 38). Para la cuestión que nos ocupa viene como anillo al dedo el caso de la monja carmelita Ana de San Bartolomé, quien aprendió a escribir a la edad de treinta años, convirtiéndose en secretaria de la santa de Ávila, en tanto que a leer lo había hecho de niña (Urkiza 1999: 13). Conforme al testimonio que aportó en el proceso de beatificación de Teresa de Jesús, fue esta quien, en el verano de 1579, estando en Salamanca, le pidió que le ayudara a responder las muchas cartas que recibía. Como la discípula aún no sabía escribir le dio como modelo "una carta de buena letra de una religiosa descalza" para que "de allí aprendiese", lo que nos advierte seguramente sobre una forma de aprendizaje practicada a menudo en los conventos; pero Ana de San Bartolomé le respondió que prefería hacerlo a partir de su letra, como así fue:

Y la santa Madre luego escribió dos renglones de su mano y dióselos; y a imitación de ellos escribió una carta esta testigo aquella tarde a las hermanas de San José de Ávila. Y desde aquel día la escribió y ayudó a responder las cartas que la Madre escribía, sin haber, como dicho tiene, tenido maestro ni aprendido a escribir de persona alguna, ni haberlo aprendido jamás, y sin saber leer más de un poco de romance, y con dificultad conocía las letras de cartas; por do conoce ser obra de Nuestro Señor para que ayudase a la Madre en los trabajos y cuidados que por su amor pasaba con tanta alegría y regocijo (Procesos 1934: 173). ${ }^{3}$

En este caso fue clave el fervor hacia la santa de Ávila y la devoción a su letra, pero la declaración de Ana de San Bartolomé es ilustrativa de un determinado modo de aprender. Al imitar la carta tomada como modelo se interiorizaba también su discurso, esto es un determinada manera de escribirlas. Lewis Carroll aludió a esta circunstancia en sus "Ocho o nueve palabras sabias sobre escritura epistolar": "si la carta es en respuesta a otra, comienza por sacar esa otra carta y leerla de arriba abajo para refrescarte la memoria, saber qué es lo que tienes que responder y cuál es la dirección actual de tu correspondencia" (Carroll 2009: 35). Claro que no hace falta acudir a un texto tan alejado de la época que estamos analizando (fue publicado en 1890), pues trescientos años antes Antonio de Torquemada ya lo apuntó en su Manual de escribientes, escrito a mediados del siglo XVI. ${ }^{4} \mathrm{Al}$ ocuparse "De las respuestas de las cartas" dice que cualquiera que sea el tipo de estas, "la respuesta ha de ser conforme a lo que se escrive" (Torquemada 1994: 197). En otro apartado del discurso sobre las cartas mensajeras se ocupa de "cómo es lícita la ynmitación a los que escriven cartas" (Ibid.: 147-150). Cualquier carta, real o ficticia, manuscrita o impresa, podía servir

\footnotetext{
${ }^{3}$ La declaración de Ana de San Bartolomé sirvió para afianzar la santidad pues corresponde a la respuesta que dio a la novena pregunta del interrogatorio: "si saben que Nuestro Seńor obró por medio e intercesión del cuerpo o reliquias de la dicha Madre después de muerta algunos milagros".

${ }^{4}$ El manuscrito no está fechado. Amado Alonso (1955) propuso que se pudo escribir en 1560, en tanto que Canellada y Zamora Vicente (1970) lo datan hacia 1552, a partir de datos biográficos proporcionados por el autor en la obra, y Martín Baños (2009) lo sitúa entre 1551 y 1559.
} 
como modelo, proporcionar pautas de estilo o enseñar el uso de los tratamientos. Pero no se trataba de trasladar sin más las cláusulas, oraciones y razonamientos vistos en otras misivas, sino de adaptarlas según procediera en cada caso. La imitación, concluye, "es buena y líçita quando se sabe hazer" (Ibid.: 149).

En determinados ambientes, esta práctica desembocó en la confección de instrumentos orientados a ese propósito, como los cuadernos de cartas copiadas, que no deben confundirse con los libros copiadores de cartas integrados por la copia de las misivas enviadas por una determinada persona. Se trata de una actividad bastante extendida entre los profesionales de la pluma y los cortesanos, según sugiere el comportamiento epistolar de Mateo Vázquez. Conforme al documentado estudio de José Luis Gonzalo Sánchez-Molero, su biblioteca y escritorio cambiaron de forma significativa tras ser nombrado secretario de Felipe II en 1573. Entre los nuevos papeles que entonces aparecen en su mesa de despacho constan "algunos curiosos cuadernos con copias de cartas y cédulas reales", entre ellos el que remitió como obsequio navideño a Juan Pérez de Alcega (Sánchez-Molero 2005: 824-825). Siendo secretario real aderezó también algunas instrucciones sobre el modo de escribir las cartas para uso de sus propios escribientes. Entre otros pormenores, en ellas apeló a la posesión de "libros de cartas italianas", además de observar que era necesario "tener atención al stilo y razones de las cartas que se van reçibiendo y respondiendo, porque assi se aprende mucho, y yo me he valido y ayudado mucho de seguir este camino" (Ibid.: 832). En fin, ese carácter propedéutico que una carta podía tener al escribir otra es evocado igualmente por Álvaro de Acuña como el mejor remedio contra la fatiga que producía la escritura, según leemos en una de las escenas de la comedia Fuego de Dios en el querer bien (1660) de Calderón de la Barca:

¡Qué fatiga es tan honrada pero fatiga en efecto, la de escribir! Bien decía un cortesano discreto que si hubiera tienda donde algún un mercader de ingenios vendiese cartas escritas, fuera el más seguro empleo del mundo. "Amigo y señor..."

(Calderón de la Barca 1987: 1258).

Al hablar de "cartas escritas" sin más, cabe suponer que aluda a esas misivas sueltas o coleccionadas a las que me he referido antes, y no tanto a los tratados y antologías epistolares impresos. Con todo, este tipo de textos también constituyeron otra herramienta propedéutica, funcionando, en el caso de los manuales, como una suerte de "secretarios de papel" (Serrano

\footnotetext{
${ }^{5}$ Aparte de esta, redactó otra instrucción para su secretario y camarero, el maestro Cespedes, acerca de cómo debía tener bien ordenado su escritorio y cómo debía tratar la correspondencia que diariamente llegaba a su casa.
} 
Sánchez 2014). De hecho, la tratadística epistolar contaba ya con una larga trayectoria (Poster

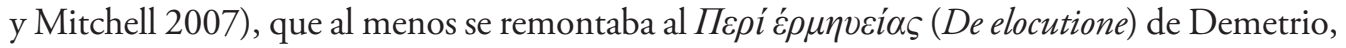
que puede fecharse en el siglo I de nuestra era (Poster 2007: 23). En dicho tratado ya se apuntaron una serie de rasgos que desde entonces han sido tópicos de la preceptiva epistolar, como la sencillez, la claridad, la brevedad, la adecuación al destinatario y cierta proximidad con el diálogo. La retórica romana profundizó en ellos y añadió otras prescripciones referidas a la disposición del escrito y a su relación con la materia que lo soporta contribuyendo a una definición del género epistolar que tuvo su máximo exponente en Cicerón. Durante las épocas carolingia y posterior se incorporaron ciertas novedades en los usos de la correspondencia escrita, como es el desarrollo de una epistolografía culta y literaria, por un lado, y la extensión de la escritura autógrafa, por otro (Petrucci 2008: 28-36). Un poco más adelante, a finales del siglo XI y durante las dos centurias sucesivas, los maestros y las escuelas de gramática y retórica promovieron el uso de los ars dictandi, esto es, textos orientados a enseñar el modo correcto de escribir las cartas junto a otros elementos de retórica (Boureau 1991). Imbuidas de este mismo espíritu, las Ordinacions de la Casa i Cort (1344) del rey Pedro IV de Aragón contienen seis capítulos referidos a los usos de la correspondencia (Ordinacions 2009: 182194). En ellos se reguló la práctica epistolar atendiendo a tres principios básicos: la colocación del nombre de la autoridad a la que se dirigía la carta antes o después del remitente, según su rango fuera superior, igual o inferior; el tratamiento que debía darse a cada destinatario; y la fórmula del saludo final (Gimeno Blay 2014: 210-215).

Como no podía ser de otro modo, el Renacimiento aportó nuevos bríos a la cultura epistolar (Pontón 2002). Según Pedro Martín Baños (2005: 16), en la Europa de los siglos XVI y XVI llegaron a circular alrededor de doscientos tratados y manuales distintos, manuscritos e impresos, en latín y en lenguas vernáculas. De los textos latinos el más representativo fue el Opus de conscribendis epistolis (Basilea: Johann Froeben, 1522) de Erasmo de Róterdam, donde su autor compendió la doctrina clásica y medieval para hacer su propia aportación al género. De todos modos, la divulgación de la actividad epistolar no solo vino dada por los tratados y formularios, orientados preferentemente a las gentes de letras y a los ministros de la pluma, es decir a quien hacían un uso regular de la correspondencia escrita, ya sea para sí mismo o para quienes servían, sino todavía más por la larga nómina de antologías epistolares que se dieron a la imprenta de aquellos tiempos. En Italia, por ejemplo, se ha estimado una producción de trescientos títulos diferentes entre 1538 y 1662 (Basso 1990).

Junto a tratados y vademécum de índole manuscrita, entre los que sobresalió en Espańa el Manual de escribientes de Torquemada, lo más relevante es la amplia nómina de obras impresas. Por lo que atañe a nuestro país, esa producción fue inaugurada por el manual catalán Art y stil per a scriure a totes persones de qualsevol estat que sien (c. 1510-1511), de Thomàs de Perpenyà. ${ }^{6}$ En lengua castellana, el honor le cupo casi cuarenta años después al Estilo

\footnotetext{
${ }^{6}$ La fecha de 1510 consta en la catalogación del ejemplar que conserva la Biblioteca Nacional de Espańa, mientras que Navarro Brotóns (1999: 24) propuso 1511. En todo caso, ambas fechas dan más antigüedad al texto que la sugerida por Mesquida Cantallops (2003: 217), quien lo ha datado 1515 y 1517.
} 
de escrevir cartas mensageras sobre diversas materias (Zaragoza: Bartolomé de Nájera, 1547) de Gaspar de Tejeda, con ediciones posteriores (1549 y 1553), seguido del Segundo libro de cartas mensageras (Valladolid: Sebastián Martínez, 1552), obra del mismo autor. Este año se publicó asimismo el Nuevo estilo de escrevir cartas mensageras (Zaragoza: Agustín Millán, 1552) del calígrafo durangués Juan de Icíar, siendo también en esa década cuando Torquemada escribió el suyo. ${ }^{7}$ A estos siguieron autores como Juan de Leras, Tomás Gracián Dantisco, Juan Vicente Pelliger, Jerónimo Paulo de Manzanares o Juan Páez de Valenzuela y Castillejo, sin descuidar los diversos secretarios publicados en el siglo XVII al amparo de una moda de dimensión europea: Dirección de secretarios de señores (Madrid: Alonso Martín de Balboa, 1613) y Secretario de señores (Madrid: Viuda de Fernando Correa, 1622), de Gabriel Pérez del Barrio, o El secretario del rey (Madrid: Luis Sánchez 1620) de Francisco Bermúdez de Pedraza, todos ellos con varias ediciones (Castillo Gómez 2006: 34-44; Amor López 2011; Serrano Sánchez 2014).

Es evidente que la carta se había impuesto como un medio de comunicación, sin que el analfabetismo fuera forzosamente un impedimento. Cuando los intercambios epistolares se hicieron necesarios, bien porque hubiera que acudir a alguna autoridad en petición de una gracia, bien para comunicarse con un familiar desplazado por la guerra o la emigración transatlántica, el desconocimiento de la escritura o la falta de destreza en el discurso epistolar se pudieron suplir acudiendo a personas del entorno cercano o bien a los escribanos públicos instalados en plazas y lugares públicos, según consta que los hubo en Barcelona, Granada, Sevilla, Toledo, Lima, Lisboa, Madrid o Málaga refiriéndome únicamente a ciudades de la monarquía hispana (Castillo Gómez 2010: 365-369). De la veintena de escrevedores de cartas que estaban asentados en el Largo del Pelourinho Velho, en Lisboa, se afirma en alguna crónica de la ciudad que no vivían solo de "de cortar plumas y notar cartas y escribirlas a gente idiota”, sino que también atendían a gentes más acomodadas. Se cuenta, en concreto, que a ellos acudió hasta un criado de Simáo de Silveira, cortesano de Juan III de Portugal, quien solicitó el saber de uno de aquellos escribanos para que, en nombre de su señor, escribiera una carta de amor a una dama (Cit. en Bouza 2001: 72-73). Dada la intensidad de los intercambios epistolares es normal que incluso de estos del Pelourinho se dijera que "nunca estao vagos" (Brandão 1990: 108), aunque otras veces allí y en otros lugares no se tuvieran tan a mano. Al menos esta fue la disculpa que Beatriz de Carvallar expuso a su padre, en una carta fechada en México el 10 de marzo de 1574, para justificar el silencio epistolar de su hermana: "Inés dice que la perdone que no escribe por falta de escribano" (Cit. en Otte 1988: 85).

Desentrañar el quehacer concreto de estos intermediarios no es fácil dada la escasez de rastros documentales, si bien podemos tratar de remediarlo con otro tipo de fuentes. A este respecto es sumamente iluminadora la escena que narra el licenciado Francisco Porras de la Cámara en su Jornada de Lisboa (ca. 1606), a propósito de los escribanos del baratillo que encontró acomodados en la plaza de la Tinta cuando visitó la ciudad portuguesa comisionado

\footnotetext{
${ }^{7}$ Sobre la distintas corrientes epistolográficas que ilustran los tratados de Tejeda, Torquemada e Icíar, Navarro Gala 2010. De manera específica sobre los modelos discursivos femeninos en Gaspar de Tejeda, Navarro Gala 2011.
} 
por el arzobispo de Sevilla. En su pintoresco relato destacan los matices que ofrece sobre una tarea tan cotidiana como la de escribir cartas misivas. La conversación que escuchó entre un varón portugués y una mujer gallega que precisaba escribir a su marido le trajo a la memoria otra similar que había acontecido con los escribientes del sevillano corral de los Olmos, bien conocidos suyos. Cierto día, dice, se presentó allí una compungida señora con el deseo de que le escribieran una carta nada condescendiente hacia quien acababa de abandonarla: "Dígale, dígale a ese traidor malvado las azquas que abrasan mi corazón y las llamas vivas que queman mi alma, y desónrremelo, que es un perro sin ley, sin rey, ni sin Dios pues dexa a una muger como yo sola en tierra ajena y tan llena de ocasiones. Y dígale, dígale la onrra con que vivo y he vivido". El escribiente trató de apaciguarla argumentando que el varón en cuestión no era su marido y hasta le sugirió que empleara un tono "más derretido y tierno", como si el destinatario fuera el mismo papa. Tampoco escatimó una llamada de atención sobre el diferente precio de las misivas: entre medio cuarto y dos reales, siendo las más caras aquéllas en las que, junto a la firma, se añadía el dibujo de "algún corazón y saetas, o algunas dos manos asidas". La mujer, sin embargo, se mantuvo en sus trece, poco propensa a tanto melindre como pretendía el amanuense. ${ }^{8}$

Inventado o no, ahora es lo de menos, el diálogo nos sitúa virtualmente en medio de las negociaciones de cultura escrita que debían producirse en esos escritorios. Podemos suponer que en situaciones de esta índole el cliente pretendería llevar el lenguaje a su terreno buscando la mayor sinceridad y espontaneidad posible, por lo menos cuando las cartas trataban de amores, correspondidos o no, afrentas y reprimendas; y que el escribano buscara aminorar tanta rabia o desasosiego valiéndose de palabras más reposadas, adaptadas a un evento de alta connotación oral pero escrito al fin. Otras veces puede que la clientela se interesara más por mensajes cifrados y lenguajes figurados, en los que a buen seguro el profesional de la pluma podía ofrecer distintas soluciones. Si las cartas iban encaminadas a personas menos próximas o comportaban una determinada petición, cabe suponer que aún fuera más necesario el oficio y consejo del escribano

\section{ESCRITURA, MATERIALIDAD Y REPRESENTACIÓN}

Escribir cartas, sobre todo en determinadas circunstancias, no era un asunto baladí. Su capacidad comunicativa se relaciona estrechamente con el respeto o no a una estructura determinada, perfectamente reconocible, expuesta con distinto detalle en los tratados epistolares. Con los matices que ya se han anotado respecto de los públicos principales y del uso efectivo de mucho de ellos, todos procuraron responder a la necesidad de educar el gesto epistolar para que este se acomodara a los fines y destinatario de cada misiva. El Art $y$ stil per a scriure de Thomàs de Perpenyà, dentro de su brevedad, contempló claramente la

${ }^{8}$ Real Biblioteca, Madrid, B II/2163, fol. 144r-145v. Cit. en "Escrivanos del baratillo” 2002 y Bouza 2004: 319-321. 
distinción que había de hacerse según la misiva fuese entre iguales, de una persona de rango menor a otra superior o en sentido inverso (Mesquida Cantallops 2003). De forma mucho más puntual, retomando principios de la retórica clásica, Antonio de Torquemada sintetizó la ceremonia epistolar en seis cuestiones que, a modo de guía, permitían escribir las cartas correctamente sin tener que ir "como el ciego, que ni sabe el camino ni tiene quien se lo enseñe":

El que començare a escrevir una carta, ponga primero en su entendimiento y tenga delante de sus ojos, como espejo en que se mire, estas seis cosas: Quién, A quién, Por qué, Qué, Cuándo, De qué manera. Porque sin ellas yrá como el çiego que ni sabe el camino ni tiene quien se lo enseñe, y aunque vaya atentando, por fuerça una vez o otra ha de dar consigo en algún despeñadero; y el que ynconsideradamente escriviere, avrá de despeñarse en algunos yerros muy profundos, y de donde tenga muy gran dificultad en salir (Torquemada 1994: 124).

Este tipo de recomendaciones sustentaban una teoría del género según la cual las cartas debían respetar y visibilizar el pacto social tratando a cada persona según su rango. La carta, por tanto, no solo es una forma de comunicar mensajes sino un artefacto cultural destinado a representar al ausente ante el destinario observando sobre el papel el respeto a las convenciones sociales (Castillo Gómez 2005; Serrano Sánchez 2015). La teoría epistolar se orientó preferentemente a las misivas, dejando de lado una tipología tan corriente como los billetes (Castillo Gómez 2014), que de hecho no aparecen incluidos en ninguno de los tratados y formularios epistolares áureos salvo en la edición madrileña del Secretario y consegero de señores y ministros de Gabriel Pérez del Barrio, impreso en 1667 en el taller de Mateo Espinosa, en el que se introduce un "formulario de cartas y villetes" (fols. 98r-108r), al que siguen "diversas cartas y villetes de favor y encomendaciones de personas y negocios" (fols. 108v-118).

A la hora de diferenciar ambos formatos resulta más provechoso acudir al Tesoro de la lengua castellana o española (Madrid: Luis Sánchez, 1611) de Sebastián de Covarrubias. Según este, la carta era "mensagería que se embía al ausente por escrito en qualquier materia que sea” (Covarrubias 2003: 312). En la definición de billete se muestra más preciso, pues alude tanto al soporte como a la habitual brevedad del mensaje, a la proximidad entre corresponsales, a la confidencialidad del contenido y a la fidelidad de los mensajeros:

El papel en que se escrive algunas pocas razones de una a otra persona que assisten en el mesmo pueblo. Fue muy buena invención para comunicarse con más quietud y tratar las cosas con secreto, no fiándolas de ningún tercero ni criado, que muchas vezes tuercen la razón y por esso los llaman estraga recados (Ibíd.: 1009).

La carta, en fin, se muestra como una práctica de escritura sumamente codificada. De acuerdo con Armando Petrucci, el conservadurismo del género debe ser entendido en 
relación a la funcionalidad de la carta, es decir, para qué cambiar aquello que resulta práctico y facilita el objetivo perseguido: la comunicación entre ausentes (Petrucci 2003: 92). Dicha estructura se articula en torno a tres partes fundamentales: proemio, discurso y fin; lo que Emanuele Tesauro, uno de los tratadistas más notables del Antiguo Régimen, llamó cabeza, cuerpo y cold:

Assí como entre los animales imperfectos, algunos ay sin cabeza, como las cigarras; otros sin cola, como los monos; otros sin cuerpo, como algunos peces marítimos y palustres, en los quales nada se ve si no cabeça y cola; pero los animales más perfectos, como el león, el tigre y el cavallo, fueron de estas tres partes proporcionadamente compuestos; assí a una carta perfecta se le piden estas tres partes bien concertadas y unidas.

El cuerpo es el discurso, compuesto de razones y argumentos sobre el thema propuesto, como queda dicho en el capítulo V. De modo que el thema no es cabeça, pero parte essencial del cuerpo, no pudiéndose separar uno de otro.

La cabeça, pues, es un adornado preámbulo para introducirse en el thema, como en las oraciones se antepone el exordio para insinuarse a la proposición; y esto principalmente quando se escrive a persona de respeto o antecedentemente no conocida, u después de un largo silencio comunicada, en cartas de negocio o en las de ruego, especialmente si falta mérito para lo que se pide, o ya sea de tal assumpto que parezca descortesía o temeridad entrar de golpe en el thema sin alegar primero alguna escusa o urgencia que obligue a la animosidad de escrivir y de vencer el encogimiento. En este proemio, pues, se puede alegar alguna razón aguda o éthica o pathética para conciliar el ánimo del letor y quitarle la estrañeza; de que a su tiempo se oirán muchos exemplares.

La cola, o remate, pues, es un cumplimiento con que acabado el discurso se usa de urbanidad, u disculpando el atrevimiento o professando perpetua obligación o anunciando prosperidad y largos años en vida feliz, con fórmulas ingeniosas o éthicas o pathéticas, conforme a los assumptos para que el fin corresponda al principio, de que se dará una pauta con estas tres partes de carta gratulatoria, o sea de enhorabuena por la vitoria de un príncipe (Tesauro 1696: 12-13).?

En cuanto artefacto verbal, la carta expresa un determinado acto discursivo valiéndose de una serie de indicadores que enuncian $y$, en consecuencia, representan tanto a la persona que escribe como a la que es destinataria de la misiva, entrelazadas ambas por el "doble pacto epistolar" al que se refirió Claudio Guillén (1991: 188-190). En el plano lingüístico dicha competencia de enunciación pasa por el uso que se hace del sistema pronominal, de los deícticos o de los tiempos verbales que recrean las distintas acciones. En el campo de la materialidad del escrito, se hace patente en la disposición del texto sobre la

${ }^{9}$ Se han respetado las cursivas del original. 
superficie donde éste se inscribe y en el modo en que se visibilizan las distintas partes del discurso epistolar, como también en la función performativa del "yo" que suscribe la carta mediante la firma autógrafa, incluso cuando lo hace a través de otro, toda vez que el acto de firmar da validez al compromiso sellado por la escritura (Fraenkel 2001).

$\mathrm{Si}$ nos detenemos a considerar el patrimonio epistolar de la temprana Edad Moderna y de personas de diferente condición social, observaremos que esos elementos suelen estar presentes en todas ellas. Lo que las distingue no es, por tanto, el respeto a una forma de escritura consolidada e interiorizada con el uso, sino la mayor o menor elaboración discursiva, el manejo de los ingredientes retóricos, el vocabulario empleado, la corrección lingüística y sintáctica, la organización del escrito o el grado de proximidad a la norma gráfica propia de cada momento, es decir, una serie de competencias que se derivan tanto del nivel de alfabetismo e instrucción de las personas como del rango del individuo y la diversa intensidad de la práctica.

La cortesía debía mostrarse en elementos internos al texto, como el adecuado uso de los tratamientos y la sencillez en el estilo, pues, al decir de Luis de Zapata, "la brevedad en el escribir y aún en el hablar es cosa muy loable, y la prolijidad y lo superfluo de grandísimo vituperio" (Zapata 1959: 138). El mismo Gaspar de Tejeda reflexiona sobre ello en varias de las cartas que ofrece como modelo, especialmente en la de "una señora a otra loándole mucho la gracia de sus cartas", donde dice:

Tiéneme tan admirada la dulçura de vuestra merced que no puedo ni quiero dexar de dezir lo que devo para que por mi mano se vea que tenéys un aparato riquísimo de palabras illustres e significantes con unos sentidos muy nuevos y para sí fuessen común en un maravilloso artificio de levantallos a ser ligítimos de bastardos. También sabéys desparzir unas flores por el discurso de las cartas que parece que nacieron para sólo dalles aquel hornamento que llevan siendo vuestras, donde no se vee ninguna sombra ni señal de afetación sino que el principio se trava del fin y el fin depende del principio, y el medio conforma lo uno con lo otro, de suerte que siempre deleyta y nunca harta lo que compone vuestra mano, todo con tan sincera facilidad y ligereza quanto yo lo hallo dificilíssimo de podello dezir como pasa (Tejeda 1553: 103v).

Al igual que el estilo, ciertos dispositivos, sobre todo los que concernían a la calidad de la escritura y a la materialidad de carta, también fueron objeto de atenta observación en los manuales epistolares. Conforme a los consejos que Francisco Rodrigues Lobo expuso en Corte na aldeia e noites do inverno (Lisboa: Pedro Craesbeeck, 1619), la buena carta debía cuidar la calidad y limpieza del papel, presentar un pautado derecho, lo que suponía escribir con orden, y las letras juntas, signo inequívoco de destreza alfabética, además de un plegado uniforme, la rúbrica sutil y el sello claro (Lobo 1992: 75). Sobre la letra, en particular, Torquemada aconsejó que fuera de buen tamaño, hermosa, regular, clara y de fácil lectura, conforme al tiempo y el lugar donde se escribe: 
Aunque me preguntáis una cosa muy notoria, os la diré. Y es que la letra ha de ser de buen tamaño, ni muy grande ni muy pequeña, hermosa, ygual, clara, de manera que se dexe bien leer, las partes, apartadas, y que sea conforme al uso del tiempo y de la tierra donde se escrive. Porque yo he visto letra tirada de proçesos, letra llana, letra subida, letra cortesana, letra cançelleresca, letra bastarda, y otras letras diferentes déstas, y en un tiempo se ha usado la una y en otro la otra, y cada una dellas en el tienpo que se usava pareçía la mejor; y así lo pareçe agora la letra bastarda y la que llaman tonda, que son lás que más se usan, a lo menos entre cortesanos (Torquemada 1994: 37).

Por encima de la sutileza estrictamente gráfica, la censura sobre la mala calidad de la letra venía motivada porque esto podía ser contraproducente para la formalización del pacto epistolar. ¡Cuántas cartas, en efecto, pueden haber dado lugar a lecturas inadecuadas por el mero hecho de estar mal escritas, nada organizadas y peor argumentadas! Siendo este uno de los argumentos centrales de una epístola de fray Antonio de Guevara a don Pedro Girón, "en la qual el auctor toca la manera del escrevir antiguo", no está de más recordar que el religioso, con su habitual retranca, terminó pidiendo al noble que enmendara el "avieso de la letra" porque él había aprendido a leer pero no a adivinar:

No quiero más dezir en la materia de vuestra carta, sino que toméys esta mía por primilla, y juntamente con esto pediros por merced no dexéys otro día apolillar la carta, y seáys tan bien servido de emmendar el aviesso de la letra, porque yo aprendí a leer y no aprendí a adevinar. Passado me ha por el pensamiento que adrede me embiastes aquesta carta de burla para darme ocasión que os respondiesse de burla, y que de puro traviesso me escrevistes assí porque os respondiesse assí; y si por caso fue este vuestro fin, pensad, señor, que de tales romerías no podéys sacar sino tales veneras (Guevara 2004: 64).

Por eso muchas de ellas siguen protocolos gráficos y materiales equiparables a los que se han apreciado en los documentos solemnes. Se vigila el tipo de papel, la tinta, la escritura y la disposición de esta sobre la página. Y es normal por esto que dichas cartas conllevaran a menudo la composición de borradores y minutas previos con objeto de conocer y sistematizar adecuadamente el contenido de la carta; e igualmente que fueran redactadas por secretarios.

Leyendo correspondencias y cartas personales puede verse la importancia asignada a la escritura para garantizar la comprensibilidad del escrito o para alcanzar uno de los objetivos esenciales a la misma: hacer presente a la persona ausente. En este sentido un elemento clave era la firma autógrafa, cuyo uso se introdujo claramente a finales del siglo XV como resultado de un proceso de transformación de la carta que condujo a su consolidación como sermo scriptum o conversación entre partes (Herold 2008). Nada mejor para mostrar el afecto y la deferencia que escribir de propia mano. Nada mejor para tranquilizar a los 
familiares en determinadas circunstancias que hacerse ver y sentir a través de la propia letra. Esta posibilidad la expresa muy bien dońa Urraca de Moscoso, en la tercera década del siglo XVI, al dudar que la carta recibida fuera realmente de su marido, Pedro Álvarez de Sotomayor: "ame puesto vuestra merced en la mayor alteraçión del mundo quando vino el moço del marqués, que me traxo una carta que la letra della yo no la conosçía ni la firma se paresçía con la vuestra" (Cit. en Rodríguez Suárez y Vázquez Bertomeu 2002: 243). ${ }^{10} \mathrm{~A}$ este menester parece innecesario señalar que la escritura de propia mano era una manera de individuar la actividad escrita y su comunicabilidad. Incluso podía servir para manifestar la alegría por haber alcanzado una mínima competencia de escritura, siendo esto lo que podemos deducir del orgullo con que algunas personas corroboraron que "esta letra es de mi mano", verbigracia según lo hizo Eugenia Gil en la carta que escribió, desde Cádiz, a su marido Bernardo Fadrique, emigrado a Nueva Veracruz, el día 28 de julio de 1712 (Cit. en Sánchez Rubio y Testón Núnez 1999: 366).

La escritura autógrafa garantizaba la intimidad del intercambio epistolar explicándose así la desconfianza con que algunos analfabetos experimentaron la necesidad de recurrir a terceros para solventar sus necesidades de comunicación por medio de cartas. La ficción áurea tiene uno de sus ejemplos máximos en Teresa Panza mientras que la documentación de archivo nos ofrece otros no menos portentosos. Valga el siguiente párrafo de una carta de María de los Reyes a su marido Francisco de Riberos, marinero emigrado a Veracruz, en 1617 para advertir tanto la existencia de la intermediación de escritura como las limitaciones que ésta podía imponer: "Que como otro me escribe supiera yo escribir, os enviara decir todo lo que siento en mi alma” (Cit. en Sánchez Rubio y Testón Núnez 1999: 294). A su vez, en las correspondencias cortesanas y diplomáticas la escritura ológrafa, tanto si afectaba a toda la carta como a una parte de la misma, introducía un signo de deferencia en el codificado lenguaje de corte, donde el número de líneas escritas de propia mano permitía valorar la estimación que a un corresponsal le merecía su destinatario (Bouza 2001: 138). En una carta del arzobispo de Sevilla don Diego de Deza y Tavera a don Pedro Fernández de Córdoba, primer marqués de Priego, escrita entre 1512 y 1515, puede apreciarse la distinción entre la parte que redacta el secretario, escrita en una letra de transición gótico-humanística, y la que corresponde al prelado, en itálica usual (Romero Tallafigo et al. 1995: 244-245). ${ }^{11}$

A nivel gráfico, la norma propuesta en los manuales epistolares tuvo más seguimiento en ámbito cortesano y en aquellas cartas que comportaban mayor respeto al destinatario o que pretendían alguna merced. Pero si algo caracteriza a la Edad Moderna, como se ha dicho más arriba, es sin duda la incorporación a la práctica epistolar de gentes de variada

\footnotetext{
${ }^{10}$ La carta de dońa Urraca forma parte del epistolario de don Pedro inserto como prueba en el pleito que se abrió contra él en 1531 por falsificación y fraude documental. Dicho conjunto epistolar está formado por 70 cartas, 25 escritas por él y 45 dirigidas a él, fechadas entre 1527 y 1528 pues algunas misivas carecen de referencias cronológicas precisas. (Ibíd.: 235-239). El proceso se conserva en el Archivo General de Simancas, Consejo Real, leg. 478.

${ }^{11}$ En esta misma obra se reproduce y transcribe otra carta, en letra humanística, de don Gonzalo Fernández de Córdoba, "el Gran Capitán”, a su sobrino don Pedro, escrita hacia 1513, que corrobora lo dicho (Ibíd.: 230-231).
} 
condición social, incluyendo a las mujeres y a las clases subalternas, entre quienes había muchas personas escasamente alfabetizadas. La desigual alfabetización y el dispar hábito epistolar se reflejó en distintas sintácticas y lingüísticas, así como en una amplia gama de interpretaciones escriturarias, cuyo particularismo pone en apuros la fineza del paleógrafo pues impide adscribirlas a las nomenclaturas habituales, pensadas sobre todo para distinguir las grafías utilizadas en las escribanías cancillerescas y notariales.

Las cartas más diestras se caracterizan por el empleo de una escritura cursiva de modulo pequeño dispuesta de forma ordenada y regular sobre el folio, en la que tampoco suelen faltar los signos de puntuación, abreviaturas, nexos y ligaduras, más evidentes cuanto más culta es la persona que escribe. Por el contrario, los testimonios epistolares de la gente común, de bastantes mujeres y, en general, de las personas poco o mal alfabetizadas adolecen de una inhabilidad al escribir que se aprecia en el módulo grande de letra, en la escritura de trazo redondeado, más dibujada que escrita, en los desequilibrios del pautado, en la incorrecta unión o separación de palabras y en el discurso continuo sin signos de puntuación que lo vertebren. En lo que concierne a las cartas de mujeres no pretendo sostener que todas presentaran las mismas características gráficas, ya que esto sería tanto como pensar en una escritura femenina que diera la espalda a la clase social de pertenencia y a las discriminaciones habidas entre ellas. De todos modos, también sabemos que la alfabetización femenina tuvo algunos contenidos distintos y a menudo se llevó a cabo en espacios diferentes (Nava Rodríguez 1995; Fraile Seco 2004; Gagliardi 2010: 25-48), por lo que puede explicarse que, a ojos de los contemporáneos, su letra se calificara de un modo distinto y que incluso ellas mismas se excusaran frecuentemente por la torpeza al escribir. Disculpas como la que Mariana de Morguiz presentó a su padre a finales de abril de 1562, atribuyendo el retraso en su respuesta al hecho de "estar en tan larga tierra [México] y no tener por quien escribir», seguido de la puntualización de que «las mujeres no tienen tanto aparejo para escribir y hacer todo lo que hombre querría como los hombres" (Cit. en Otte 1988: 43), engarzan bien con las dificultades que las mujeres tuvieron en el acceso a la escritura, sobre todo en los siglos XVI y XVII (Baranda Leturio 2005: 65-90). En cualquier caso, cartas sin "aparejo" las hallamos igualmente entre los varones coetáneos, del mismo modo que otros epistolarios femeninos dan testimonio de una práctica más competente atestiguada en el trazo cursivo y ágil, las letras unidas, las palabras separadas o en el conocimiento de las abreviaturas corrientes en la época.

En fin, aunque es indiscutible que la competencia gráfica no siempre es pareja a la posición social que ocupa quien escribe, no por ello se ha de despreciar la repercusión que siempre tienen las desigualdades sociales y de género. Entonces más que ahora, es evidente que todas las personas no tuvieron las mismas oportunidades en cuanto a la adquisición y uso de la escritura. Estas apreciaciones, por supuesto, pueden ser matizadas. Dejando de lado los casos extremos de las gentes de letras y las clases subalternas, no debe olvidarse que en muchas ocasiones, por arriba y por abajo, la tarea de escribir recayó en intermediarios cualificados, ya fueran los secretarios de reyes, nobles y administradores, ya los funcionarios de la administración o bien los escribientes apostados en calles y plazas, evocados más arriba. 


\section{Conclusiones}

Con desigual atención, manuales epistolares, epistolarios varios y testimonios literarios suelen recordar el cuidado que debía ponerse al escribir una carta, ora en los interiores (estilo, argumentos, títulos y cumplimientos), ora en los exteriores (papel, organización y disposición, tipo gráfico, plegado y sellado). Se trataba, en suma, de explicitar un orden de la escritura que también lo era de las convenciones sociales y de las funciones desempeñadas por las distintas modalidades epistolares. No atender tales preceptos podía entrañar una falta de respeto e influir en la inoperancia de una práctica de escritura cimentada en el pacto de comprensibilidad formulado entre emisor y destinatario. De ahí que el por entonces predicador y confidente de Carlos I, fray Antonio de Guevara, censurara el mal escribir en una carta a don Pedro Girón basándose en que el papel era grueso, la tinta blanca, los renglones torcidos, las letras trastocadas y las razones borradas:

He querido, señor, contaros estas antigüedades para esta vuestra carta si fue escripta con cuchillos o con hierros, o con pinceles, o con los dedos, porque según ella vino tan ininteligible, no es possible menos sino que se escrivió con cańa cortada o con cañón por cortar. Sabed, señor, que las condiciones de vuestra carta eran ser el papel gruesso, la tinta blanca, los renglones tuertos, las letras trastrocadas y las razones borradas, de manera que o vós, señor, la escrevistes a la luna, o algún niño que era aprendiz en la escuela (Guevara 2004: 62).

Para el objeto abordado en este artículo poco importa que el testimonio proceda de una carta fingida, como lo fueron, por otro lado, muchas de las que se divulgaron a través de la imprenta, y aún menos que su contenido fuera inducido por el caudillaje comunero del noble castellano. Al contrario, los razonamientos que el eclesiástico expuso al reprobar el mal gesto epistolar de su correspondiente son relevantes y dignos de atención por la importancia que asignan a las buenas maneras epistolares; la misma que, según hemos visto, puede rastrearse en los tratados y formularios concebidos para regular dicho ceremonial. Mientras que algunos están formados por un repertorio de modelos de cartas a distintas autoridades y para diferentes situaciones, otros contienen el discurso teórico del género. Estilo y forma permitían identificar el origen y el cometido de cada misiva a la vez que eran una manera de evidenciar el poder y la distinción social, siendo por ello dichas formalidades más apremiantes entre los corresponsales diplomáticos, en los intercambios epistolares más sujetos a la etiqueta cortesana o en las cartas encaminadas a los poderosos. En circunstancias así no valía cualquier clase de papel o de tinta y menos aún descuidar la escritura o servirse de "letras trastrocadas". Fray Antonio de Guevara reprobó a Pedro de Girón porque, en función de la mala letra, su carta parecía escrita a la luz de la luna, y similares disculpas las hallamos en las cartas efectivas. Así, en una de Francisco de Espinosa a su hermano Manuel, escrita desde Panamá a 23 de agosto de 1737, aquél excusaba las erratas por haber escrito a las nueve de la noche y con calentura: "Vuestra merced perdonará las herratas de esta, pues 
es escrita a las nuebe de la noche y con calentura por anticipar a vuestra merced esta noticia" (Cit. en Martínez Martínez 2007: 420). En suma, atender los requerimientos del buen hacer epistolar implicaba velar tanto por los dispositivos materiales, el sobre y la escritura, como por las condiciones en las que se escribía.

La relación que se establece entre los recursos propios del orden de las palabras gráfico, lingüístico y literario- cristaliza en una realidad varia y desigual de apropiaciones epistolares. Asumir que las cartas explicitan la complicidad que se establece entre la persona que escribe (o manda hacerlo) y aquélla a quien va destinada entrańa la contingencia de pensarlas e interpretarlas en cuanto que enunciados performativos, es decir, como textos que, además de verbalizar las circunstancias más diversas, las hacen realidad al ponerlas por escrito. No cuesta admitir esta potencialidad si tenemos presente el valor que podía alcanzar una carta en manos de su destinatario, bien por la naturaleza de las confidencias y noticias compartidas, bien porque diera solución a algún asunto pendiente, bien porque tramitara cualquier petición o bien, sencillamente, porque diera visibilidad a la persona ausente. De ahí la ilusión y alegría que provocaba la llegada de la carta de un ser querido (o la tristeza si se retrasaba): "Hijo de mi alma: Un pliego tuyo recibí, su fecha en San Juan de Ulúa, y fue tanto el gozo que esta miserable vieja sintió que me tuvieron por muerta por más de dos horas del gran contento que recibí de que hubiese llegado con salvamento de los trabajos y peligros de la mar". ${ }^{12}$

\section{OBRas CitADAS}

Alonso, Amado. 1955. De la pronunciación medieval a la moderna en español. 2 vols. Madrid: Gredos (2a. ed., 1967).

Álvarez, Tomás. 2001. "El venerable Juan de Palafox ante las cartas de Santa Teresa. Desde la primera edición francesa hasta la primera traducción española". Palafox: Iglesia, Cultura y Estado en el siglo XVII. Coord. Ricardo Fernández Gracia. Navarra: Universidad de Navarra, 339-352.

Amor López, Silvia. 2011. "Els manuals epistolars impresos a Catalunya (segles XVI, XVII i XVIII)". Manuscrits: Revista d'història moderna 8: 65-84.

Antón Pelayo, Javier, ed. 2011. "Les pràctiques epistolars (segles XVI-XIX)", dossier monográfico de Manuscrits: Revista d'història moderna 29: 17-114.

Baranda Leturio, Nieves. 2005. Cortejo a lo prohibido. Lectoras y escritoras en la España moderna. Madrid: Arco/Libros.

Basso, Jeannine. 1990. Le genre épistolaire en langue italienne (1538-1662). Répertoire chronologique et analytique. 2 vols. Nancy: Presses universitaires de Nancy.

\footnotetext{
${ }^{12}$ Carta de María Capacha Monsalve a su hijo don Diego Tavira Toledo, emigrado a México, escrita en Granada, 29 de febrero de 1618. Cit. en Sánchez Rubio y Testón Núńez I999: 295. A propósito de las emociones despertadas por la llegada de las cartas de familiares, Castillo Gómez 2009.
} 
Bermúdez de Pedraza, Francisco. 1620. El secretario del rey. Madrid: Luis Sánchez.

Boureau, Alain. 1991. "La norme épistolaire, une invention médiévale". La correspondance.

Les usages de la lettre au XIX" siècle. Dir. Roger Chartier. París: Fayard, 127-157.

Bouza, Fernando. 2001. Corre manuscrito. Una historia cultural del Siglo de Oro. Madrid: Marcial Pons.

- -. 2004. "Los contextos materiales de la producción cultural". España en tiempos del Quijote. Dir. Antonio Feros y Juan Gelabert, Madrid: Taurus, 309-344.

- - -. coord. 2005. Cultura epistolar en la alta Edad Moderna. Usos de la carta y de la correspondencia entre el manuscrito y el impreso. Madrid: Universidad Complutense de Madrid (Cuadernos de Historia Moderna. Anejos, IV).

Braida, Lodovica. 2009. Libri di lettere: le raccolte epistolari del Cinquecento tra inquietudini religiose e "buon volgare". Roma-Bari: Laterza.

Brandão, João. 1990. Grandeza e abastança de Lisboa em 1552. Ed. José da Felicidade Alves. Lisboa: Horizonte.

Calderón de la Barca, Pedro. 1987. Fuego de Dios en el querer bien. Id. Obras completas, tomo I. Comedias. Ed. Ángel Valbuena Briones. Madrid: Aguilar, 1250-1288.

Carroll, Lewis. 2009. "Ocho o nueve palabras sabias sobre escritura epistolar". Id. Alimentar la mente. Trad. Carlos García Simón. Madrid: Gadir, 21-69.

Castillo Gómez, Antonio. 2005. “'El mejor retrato de cada uno'. La materialidad de la escritura epistolar en la sociedad hispana de los siglos XVI y XVII". Hispania. Revista española de Historia, LXV/3, 221, 847-876.

- - - 2006. Entre la pluma y la pared. Una historia social de la escritura en los siglos de Oro. Madrid: Akal.

- - . 2009. "Escribir las emociones. Calas en las cartas privadas de la emigración a Indias (siglos XVI-XVII)". Páginas de Guarda. Revista de Lenguaje, Edición y Cultura Escrita $8,144-158$.

- - . 2010. "Cultura escrita y actividad escribanil en el Siglo de Oro". El nervio de la República: El oficio de escribano en el Siglo de Oro. Ed. Enrique Villalba y Emilio Torné. Madrid: Calambur, 351-370.

- - . 2013. 'Muchas cartas tengo escritas'. Comunicació epistolar i correu a l'Espanya moderna". Communicatio: un itineari històric. Ed. Josep. A. Iglesias Fonseca. Molina de Segura (Murcia): Nausícaä / Universitat Autònoma de Barcelona, 133-164.

- - -. 2014. "Mensajes efímeros. Escribir billetes en el Siglo de Oro hispánico". CartasLettres-Lettere. Discursos, prácticas y representaciones epistolares (siglos XIV-XX). Dir. Antonio Castillo Gómez y Verónica Sierra Blas. Alcalá de Henares: Universidad de Alcalá, 365-389.

Covarrubias, Sebastián de. 2003. Tesoro de la lengua castellana o española. Ed. Martín de Riquer. $5^{a}$ ed. Barcelona: Altafulla. Edición facsímil de la realizada por el impresor Horta, Barcelona, 1943.

Dadson, Trevor J. 1999. Libros. lectores y lecturas. Estudios sobre bibliotecas particulares espanolas del Siglo de Oro. Madrid: Arco/Libros. 
Egido, Aurora. 2012. "La dignidad humanística de la escritura”. Bulletin Hispanique. 114/1, 9-39

'Escrivanos del baratillo'. Una imagen en la jornada lisboeta de Francisco Porras de la Cámara”. 2002. Avisos. Noticias de la Real Biblioteca, Año VIII, 31, <http://avisos.realbiblioteca.es $/$ ? $\mathrm{p}=$ article\&aviso=40\&art=923>. Acceso 9 de sept. de 2017.

Fraenkel, Béatrice. 2001. "La firma como exposición del nombre propio". El nombre propio. Su escritura y significado a través de la historia en diferentes culturas. Comp. Anna-Marie Christin. Barcelona: Gedisa, 213-228 (ed. original, 1998).

Fraile Seco, David. 2004. "Mujer y cultura: la educación de las mujeres en la Edad Moderna. Foro de Educación. 4, 74-88.

Gagliardi, Donatella. 2010. Urdiendo ficciones: Beatriz Bernal, autora de caballerias en la España del XVI. Zaragoza: Prensas Universitarias de Zaragoza.

Garriga Espino, Ana. 2015. "El desafío editorial de las cartas de Teresa de Jesús”. Edad de Oro, XXXIV, 135-53.

Gimeno Blay, Francisco M. 2014. “Si necessitat s'esdevenia a escriure'. Escritura y gobierno en la Corona de Aragón (siglo XIV)". Monarquía, crónicas, archivos y cancillerías en los reinos hispano-cristianos: siglos XIII-XV. Coord. Esteban Sarasa Sánchez. Zaragoza: Institución Fernando el Católico, 185-221.

Gonzalo Sánchez-Molero, José Luis. 2005. "Mateo Vázquez de Leca, un secretario entre libros. 1. El escritorio". Hispania. Revista española de Historia, LXV/3, 221, 813-846.

Graff, Harvey J. ed. 1981. Literacy and Social Development in the West: a reader. Cambridge: Cambridge University Press.

- - ed. 1987. The Legacies of Literacy: Continuities and Contradictions in Western Culture and Society. Bloomington: Indiana University Press.

Grendler, Paul F. 1989. Schooling in Renaissance Italy: Literacy and Learning, 1300-1600. Baltimore, Maryland: Johns Hopkins University Press.

Guevara, Fray Antonio de. 2004. Obras completas, III. Epistolas familiares. Ed. Emilio Blanco. Madrid: Fundación José Antonio de Castro.

Guillén, Claudio. 1998. "La escritura feliz: literatura y epistolaridad" [1991]. Id. Múltiples moradas. Ensayo de literatura comparada. Barcelona: Tusquets, 177-233.

Gutiérrez Cabero, Ángel Manuel. 2015. La enseñanza de la caligrafía en España a través de los Artes de Escribir de los siglos XVI al XX: la construcción de un estilo de escritura. Madrid: CreateSpace Independent Publishing Platform.

Herold, Jürgen. 2008. "Von der 'tertialitas' zum 'sermo scriptus'. Diskurswandel im mittelalterlichen Briefwesen und die Entstehung einer neuen Briefform von der Mitte des 13. bis zum Ende des15. Jahrhunderts". Briefe in politischer Kommunikation vom Alten Orient bis ins 20. Jahrhundert - Le lettere nella comunicazione politica dall' Antico Oriente fino al XX secolo. Ed. Christina Antenhofer y Mario Müller. Göttingen: V\&R unipress, 83-113.

Herreros Jiménez, Mauricio y Ma. Gloria Diéguez Orihuela. 2008. Primeras letras. Aprender a leer y escribir en Valladolid en el siglo XVI. Valladolid: Universidad de Valladolid. 
Honcala, Antonio de. 1546. Pentaplon christianae pietatis. Alcalá de Henares: Juan de Brocar.

Icíar, Juan de. 1552. Nuevo estilo de escrevir cartas mensageras sobre diversas materias. Zaragoza: Agustín Millán.

Lobo, Francisco Rodrigues. 1991. Corte na aldeia [1619]. Ed. Jose Adriano de Freitas Carvalho. Lisboa: Editorial Presença.

Lucas, Francisco. 2005. Arte de escribir. Facsimil de la edición de Madrid, Francisco Sánchez, 1580 (BNE, R/2753). Introducción de Ana Martínez Pereira. Madrid: Calambur.

Manzanares, Jerónimo Paulo de. 1607. Estilo y formulario de cartas familiares. Madrid: Alonso Martín.

Martin Baños, Pedro. 2005. El arte epistolar en el Renacimiento europeo, 1400-1600. Bilbao: Universidad de Deusto.

- - - 2009. "Fuentes de la doctrina epistolar del Manual de escribientes (c. 1551-1559) de Antonio de Torquemada: materiales para una edición anotada". Humanismo y pervivencia del mundo clásico: Homenaje al profesor Antonio Prieto. Vol. IV. 3. Ed. José María Maestre Maestre, Joaquín Pascual Barea y Luis Charlo Brea. Alcañiz: Instituto de Estudios Humanísticos; Madrid: Consejo Superior de Investigaciones Científicas; Cáceres: Universidad de Extremadura; León: Universidad de León; Zaragoza: Universidad de Zaragoza; Teruel, Centro de Estudios Turolenses, 1409-1427.

Martínez Martínez, Carmen. 2007. Desde la otra orilla. Cartas de Indias en el Archivo de la Real Chancillería de Valladolid (siglos XVI-XVIII). León: Universidad de León.

Martínez Pereira, Ana. 2006. Manuales de escritura de los Siglos de Oro. Repertorio crítico y analitico de obras manuscritas e impresas. Mérida: Editora Regional de Extremadura.

Mesquida Cantallops, Joan Antoni. 2003. "L'Art y stil para scriure a totes persones de qualsevol estat que sien. E diverses maneres de comptes abreviats necessaris per a totes persones, de Thomàs de Perpenyà: un manual de correspondència de princips del segle XVI". Actes del dotzè Col.loqui internacional de llengua i literatura catalanes, Universitat de París IV-Sorbonne, 4-10 de septiembre de 2000. Vol. 3. Montserrat: L'Abadia de Montserrat, 317-329.

Nava Rodríguez, María Teresa. 1992. La educación en la Europa Moderna. Madrid: Síntesis. Navarro Brotóns, Víctor. 1999. Bibliographia physico-mathematica hispanica (1475-1900). I. Libros y folletos (1475-1600). Valencia: Universitat de València-Consejo Superior de Investigaciones Científicas.

Navarro Gala, María Josefa. 2010. "Debate e interacción doctrinal en las artes epistolares castellanas de mediados del siglo XVI". Dicenda: Cuadernos de Filología hispánica, $28,117-140$.

- - . 2011. "Los modelos discursivos femeninos en la preceptiva epistolar: la 'Cosa nueva' de Gaspar de Texeda", Estudios humanisticos. Filología, 33, 219-243.

Ordinacions de la Casa i Cort de Pere el Ceremoniós. 2009. Ed. Francisco M. Gimeno Blay, Daniel Gozalbo y Josep Trench. Estudio introductorio de Francisco M. Gimeno Blay. Valencia: Universitat de València.

Ortega-Costa, Milagros. 1978. Proceso de la Inquisición contra María de Cazalla. Madrid: 
Fundación Universitaria Española.

Otte, Enrique. 1988. Cartas privadas de emigrantes a Indias, 1540-1616. Sevilla: Junta de Andalucía, Consejería de Cultura.

Perpenyà, Thomás. (c. 1510-1511). Art y stil per a scriure a totes persones de qualsevol estat que sien. s. l.: s. i.

Pérez del Barrio, Gabriel. 1613. Dirección de secretarios de señores y las materias, cuidados y obligaciones que les tocan. Madrid: Alonso Martín de Balboa.

- - . 1622. Secretario de señores y las materias, cuidados y obligaciones que le tocan, estilo y exercicio del. Madrid: Viuda de Fernando Correa, 1622.

- - -.1667. Secretario y consegero de señores y ministros: cargos, materias, cuydados, obligaciones y curioso agricultor de quanto el govierno y la pluma piden para cumplir con ellos: el indice las toca y están ilustradas con sentencias, conceptos y curiosidades no tocadas. Madrid: Mateo Espinosa.

Petrucci, Armando. 2003. La ciencia de la escritura. Primera lección de paleografía. Buenos Aires: FCE (edición original, 2002).

- - . 2008. Scrivere lettere. Una storia plurimillenaria. Roma-Bari, Laterza.

Pontón, Gonzalo. 2002. Correspondencias. Los orígenes del arte epistolar en España. Madrid: Biblioteca Nueva.

Poster, Carol y Linda C. Mitchell, ed. 2007. Letter-Writing Manuals and Instruction from Antiquity to the Present. Historical and Bibliographic Studies. Columbia: The University of South Carolina Press.

Poster, Carol. 2007. "A Conversation Halved. Epistolary Theory in Greco-Roma Antiquity". Letter-Writing Manuals ans Instruction, cit. 21-51.

Procesos de beatificación y canonización de Santa Teresa de Jesús. 1934. Ed. Silverio de Santa Teresa. Biblioteca Mística Carmelitana, 18. Burgos: Tipografía de "El Monte Carmelo".

Rodríguez Suárez, Ma. del Pilar y Mercedes Vázquez Bertomeu. 2002. "Usos epistolares de la nobleza gallega a principios del siglo XVI: el ejemplo de D. Pedro Álvarez de Sotomayor". La correspondencia en la historia. Modelos y prácticas de la escritura epistolar. Actas del VI Congreso Internacional de Historia de la Cultura Escrita, vol. I. Ed. Carlos Sáez y Antonio Castillo Gómez, Madrid: Calambur, 231-245.

Romero Tallafigo, Manuel, Laureano Rodríguez Liañez y Antonio Sánchez González. 1995. Arte de leer escrituras antiguas. Paleografia de lectura. Huelva: Universidad de Huelva.

Sánchez Herrero, José y Ma ${ }^{a}$. Silvia Pérez González. 1998. "Aprender a leer y escribir, libros y librería en la Sevilla del último cuarto del siglo XV”. Edad Media: Revista de Historia $1,47-90$.

Sánchez Rubio, Rocío e Isabel Testón Núñez. 1999. El hilo que une. Las relaciones epistolares en el Viejo y el Nuevo Mundo (siglos XVI-XVIII). Cáceres-Mérida, Universidad de Extremadura-Editora Regional de Extremadura.

Serrano Sánchez, Carmen. 2014. 'Secretarios de papel'. Los manuales epistolares en la España moderna (siglos XVI-XVII”. Cinco siglos de cartas. Historia y prácticas epistolares en 
las épocas moderna y contemporánea. Dir. Antonio Castillo Gómez y Verónica Sierra Blas. Huelva: Universidad de Huelva, 77-95.

- - -. 2015. "Espejos del alma. La evocación del ausente en la escritura epistolar áurea”. Culturas del escrito en el mundo occidental. Del Renacimiento a la contemporaneidad. Ed. Antonio Castillo Gómez. Madrid: Casa de Velázquez, 67-80.

Tejeda, Gaspar de. 1547. Cosa nueva: este es el estilo de escrevir cartas mensageras sobre diversas materias. Zaragoza: Bartolomé de Nájera.

- - - 1552. Segundo libro de cartas mensageras, en estilo cortesano, a infinitos propósitos. Con las diferencias de cortesías y sobre escriptos que se usan. Valladolid: Sebastián Martínez.

- - . 1553. Cosa nueva. Primero libro de cartas mensageras, en estilo cortesano, para diversos fines y propósitos. Con los títulos y cortesías que se usan en todos los estados. Valladolid: Sebastián Martínez.

Tesauro, Emanuele. 1696, Arte de cartas misivas, o méthodo general para reducir al papel quantas materias pide el politico comercio. Valencia: Jaime de Bordázar.

Testón Núñez, Isabel y Rocío Sánchez Rubio. 2008. 'De todo he estado ignorante por no haber visto letra de vuesa merced'. La correspondencia epistolar como vehículo de comunicación en la sociedad moderna”. Homenaje a don Antonio Domínguez Ortiz. Granada: Universidad de Granada, 771-798.

Torquemada, Antonio. 1970. Manual de escribientes. Ed. Ma. Josefa Canellada de Vicente y Alonso Zamora Vicente. Biblioteca Real Academia Española. Anejo XXI. Madrid: Real Academia Española.

- - . 1994. Obras completas, I: Manual de escribientes - Coloquios satíricos - Jardín de flores curiosas. Ed. Mila Olano, Matilde París y Gabriela Bustelo. Madrid: Fundación José Antonio de Castro-Turner.

Urkiza, Julián. 1998. “Introducción general”. Ana de San Bartolomé. Obras completas. Ed. Julián Urkiza. Burgos: Editorial Monte Carmelo, 5-17.

Usunáriz, Jesús Ma. 2015. "Cartas de amor y cartas de emigrantes como prueba judicial en España (siglos XVI-XVIII)”. Hispanic Research Journal, 16 (4), 296-310.

Viñao Frago, Antonio. 1999. "Alfabetización y primeras letras (siglos XVI-XVII)". Escribir y leer en el siglo de Cervantes. Comp. Antonio Castillo Gómez. Barcelona: Gedisa, 39-84.

Vives, Juan Luis. 1987. Diálogos sobre la educación. Traducción, introducción y notas de Pedro Rodríguez Santidrián. Madrid: Alianza Editorial.

Zapata, Luis de. 1959. Miscelánea [ca. 1593]. Memorial Histórico Español, XI. Madrid: Imprenta Nacional. 
